\title{
Studies on the effect of Ni \& Ba co-doping on CdS nano structures
}

\author{
K. Kasirajan ${ }^{1}$, M. Karunakaran ${ }^{2} *$, N. Subhalakshmi ${ }^{3}$, S. Prabakaran ${ }^{4}$ \\ 1,2,3,4 Department of Physics, Alagappa Government Arts College, Karaikudi, India- 630003 \\ *Corresponding Author: tvdkaruna@gmail.com, Tel.: +91-8122841591
}

Available online at: www.isroset.org

Received: 18/Apr/2019, Accepted: 08/May/2019, Online: 30/Jun/2019

\begin{abstract}
The pure and various metals ( $\mathrm{Ni}$ and $\mathrm{Ba}$ ) doped Cadmium Sulphide (CdS) nano particles were successfully synthesized by chemical co-precipitation method using analytical grade Cadmium Chloride and Sodium Sulphide chemicals. The prepared samples were characterized by X-ray diffraction (XRD), Scanning electron microscopy (SEM), and Optical absorption (UV- Vis) studies. The XRD results showed that the all prepared samples were polycrystalline with hexagonal structure. The peaks were identified and compared with JCPDS (File No. 89-2944) values. From the SEM studies, the particles agglomerations are decreased by the addition of metal dopants and the average grain size of the particles are found in the range $500 \mathrm{~nm}$. The optical properties have been characterized. The obtained band gap values are $2.56 \mathrm{eV}, 2.54 \mathrm{eV}, 2.35 \mathrm{eV}$ and 2.48 $\mathrm{eV}$. The band gap is reduced and the crystallization is increased in the $\mathrm{Ni}$ and $\mathrm{Ba}$ doped $\mathrm{CdS}$ nano particles are more suitable for fabrications of Opto electronic studies.
\end{abstract}

Keywords-Cadmium Sulphide, Nano particles, X-ray diffraction, Scanning Electron Microscope, Optical studies.

\section{INTRODUCTION}

Semiconductor nano crystals are of great interests for both fundamental research and industrial development. This is due to their unique size-dependent optical and electronic properties and their exciting utilization in the fields of lightemitting diode [1], electrochemical cells [2], laser [3]. The usual preparation technique of nano crystals are by liquid reaction system at high temperatures for several hours, making those methods either expensive, explosive, moisture sensitive, extreme toxic, and energy consuming. Recently, much attention was paid to develop liquid-liquid approach for synthesis of nano crystal metals, metal oxides and metal sulfides $[4,5]$. Particularly, semiconductor nano particles have been attracting much attention because of their characteristic properties resulting from the quantum size effect which are significantly different from those of the corresponding bulk material [6-13]. In particular, sulfides of transitional metals acquired attention for applications such as sensors, optical filters, solar cells, and photovoltaic systems among others because the optical properties characteristic of the size and morphology of the crystal, essentially characterized by the transition phase from the electrical conductivity [14]. CdS (Cadmium Sulphide) particles are IIVI semiconductor materials with the band gap $2.42 \mathrm{eV}$. They show very good physical and chemical properties thus the nanocrystalline semiconductor materials having wide range band gaps. [15, 16], CdS is an important semiconductor photo catalyzer. In order to explore more suitable applications or acquire the enhanced properties, different morphological CdS nano materials have been synthesized by sputtering, vapour-phase condensation, sol-gel reaction, micro emulsion reaction, template-assisted reaction, chemical hydrolytic reaction, etc $[17,18]$. It has also extended applications in light emitting diodes Several methods have been developed to synthesize $\mathrm{CdS}$ with divergent morphologies and structures such as solvo thermal method [19], hydrothermal method [20], photochemical method[21], one pot synthesis method [22], chemical precipitation method [23] etc. Among them, chemical precipitation method is a simple, clean and inexpensive technique to obtain CdS nano particles [24]. Nano crystalline $\mathrm{CdS}, \mathrm{CdTe}, \mathrm{CdSe}, \mathrm{ZnSe}$ and $\mathrm{PbS}$ have been synthesized by a variety of methods including precipitation, sputtering, electrochemical deposition and inverse micelles. A reduction in the particle size strongly influences the crystallinity, melting point and structural stability. In the present work, $\mathrm{Ni}$ and $\mathrm{Ba}$ co-doped $\mathrm{CdS}$ nano particles were prepared via cost effective, facile chemical co-precipitation method at room temperature and the structural, morphological, Optical studies and chemical synthesis of these nano particles were investigated.

\section{Materials AND MethodS}

In the present work, we have synthesized cadmium sulphide (CdS) nano particles by simple and low cost co-precipitation method using Cadmium Chloride $\left(\mathrm{CdCl}_{2} .5 \mathrm{H}_{2} \mathrm{O}\right)$ and Sodium Sulphide $\left(\mathrm{Na}_{2} \mathrm{~S}\right)$ are used as cationic and anionic precursors. 
All the chemicals used in the experiment of (A.R) grade without further purification. In typical synthesis, desired molar proportions of Cadmium Chloride (5.829gms, $0.5 \mathrm{M}$ ) are dissolved in $50 \mathrm{ml}$ ultrapure de-ionized water. Later stirring the solution at $80{ }^{\circ} \mathrm{C}$ for $80 \mathrm{~min}, \mathrm{Na}_{2} \mathrm{~S}$ solution taken in a burette and was drop wisely added to the solution under constant stirring which was continued for 5 hours to get fine precipitation. The obtained precipitate was washed with deionized water several times. Finally, the powders were dried and annealed for 2 hours at $400^{\circ} \mathrm{C}$, the orange color $\mathrm{CdS}$ powder was obtained. For $\mathrm{Ni}$, Ba co-doped $\mathrm{CdS}$ nano particles, the appropriate amount of $\mathrm{NiCl} 2.6 \mathrm{H} 2 \mathrm{O}(10 \%)$ and $\mathrm{BaCl}_{2} \cdot 2 \mathrm{H}_{2} \mathrm{O}(10 \%)$ were added to the cationic precursor solution. Thus undoped and doped $\mathrm{CdS}$ nano particles were synthesized by the same procedure. Final CdS nano particles are used to study its micro structural, morphological and optical properties.

\section{RESULTS AND DISCUSSION}

The structural studies using XRD patterns obtained for undoped and $\mathrm{Ni}, \mathrm{Ba}$ and $\mathrm{Ni} \& \mathrm{Ba}$ co-doped $\mathrm{CdS}$ nano particles are shown in figure 4.1 and they exhibit hexagonal structure as per the standard JCPDS card no. 89 - 2944. The $2 \theta$ values of the diffraction peaks are observed at $24.82^{\circ}$, $26.53^{\circ}, 28.19^{\circ}, 36.64^{\circ}, 43.69^{\circ}, 47.87^{\circ}, 51.85^{\circ}, 52.81^{\circ}, 66.80^{\circ}$, $69.28^{\circ}, 72.42^{\circ}$ and $77.89^{\circ}$ respectively which corresponds to reflections from (100), (002), (101), (102), (110), (103), (112), (201), (203), (210), (114) and (204) planes for all samples of $\mathrm{CdS}$ nano particles. The predominant peak at $28.19^{\circ}$ indicates that $\mathrm{CdS}$ is preferentially oriented along plane (101). No other diffraction peaks corresponding to doped metal or other impurity phases were observed in diffraction patterns. All the peaks from metal content doped samples have intense sharpness of peaks and is suggested that the good crystalline nature of the pure $\mathrm{CdS}$ nano powders.

The enlarged portion of XRD patterns for $2 \theta$ values between $26^{\circ}$ to $29.5^{\circ}$ is presented in Fig. 4.2. From figure 4.2 (b), the (101) peak position is shifted a little towards higher angles with increase of the Ni content. This could be due to the $\mathrm{CdS}$ lattice modification by the $\mathrm{Ni}(10$ at.\%) doping because of the difference in radii of $\mathrm{Cd}(0.98 \AA)$ and $\mathrm{Ni}(0.74 \AA)$ which is consist with the earlier reports on $\mathrm{Ni}$ - doped CdS systems [25]. This may confirms the formation of pure Ni doped CdS particles.

With increasing $\mathrm{Ba}$ concentration, the peak (101) slightly shift to lower angle which indicates the decreased lattice parameter in $\mathrm{Ba}(10$ at.\%) doped CdS samples. This is an expected result as the ionic radius of $\mathrm{Ba}(1.35 \AA)$ is larger than $\mathrm{Cd}(0.98 \AA)$. Wang et. al. [26] reported a shift of diffraction peak towards the lower angle indicating the expansion of $\mathrm{CdS}$ nano particles with $\mathrm{Ba}$ doping. but for $\mathrm{Ni}$
\& Ba co-doped CdS does not altered the diffraction peaks as compared pure $\mathrm{CdS}$ nano material.

Figure 1 (a-d) shows the typical X-ray diffraction pattern obtained for the undoped and $\mathrm{Ni} \& \mathrm{Ba}$ doped $\mathrm{CdS}$ nano particle. The ' $d$ ' (interplanar spacing) value is decreased for $\mathrm{Ni}(10$ at. \%) doped CdS and increased for Ba (10 at. \%) doped CdS naoparticels but for Ni \& Ba co-doped CdS has same compared to the pure CdS nano material. These results implies that $\mathrm{Ni}^{2+}$ and $\mathrm{Ba}^{2+}$ have been incorporated into the crystal lattice of $\mathrm{CdS}$, thus brings contraction and elongation in the observed 'd' spacing values of doped CdS samples.

The lattice constants ' $a$ ' and 'c' values varied with dopants, but (c/a) ratio remain constant. It may assign by the presence of dopant contents (or) it was aroused due to the lattice contraction in nano structure but this lattice constant variation does not altered the crystal structure of $\mathrm{CdS}$. The lattice constant $\mathrm{CdS}$ nano particles are calculated using the following formula,

$$
\frac{1}{d^{2}}=\frac{4\left(h^{2}+h k+k^{2}\right)}{3 a^{2}}+\frac{1^{2}}{c^{2}}
$$

The (c/a) ratio calculated from the lattice constants ' $a$ ' and 'c' are found to be has closely constants compared to standard values.

The broad peaks in the sample (a), which indicates that the dimensions of CdS particles has small in size. This is the main reason for the sample (a) has lowest crystallite size compared to the other doping CdS particles of. The observed sharp and high intensity peaks in samples (b), (c) and (d), which indicate the increased crystalline nature by the addition of dopant elements. The average crystallite sizes are calculated using Debye - Scherrer's formula [27],

$$
\mathrm{D}=\frac{k \lambda}{\beta \operatorname{Cos} \theta}
$$

In $\mathrm{Ba}$ doped $\mathrm{CdS}$ has highest crystallite size $(77 \mathrm{~nm})$ which may attribute the largest ionic radius of $\mathrm{Ba}(1.35 \AA)$ compared to the host $\mathrm{Cd}(0.98 \AA)$. Microstrain values are varied due to the increased crystallite sizes [28].

Dislocation density can be evaluated from crystalline size (D) by following relation

$$
\delta=\frac{1}{D^{2}}
$$

The origin of micro strain is related to lattice misfit which is related to lattice misfit which in turn depend upon the deposition condition. The micro strain $(\varepsilon)$ developed in thin films can be evaluated from the relation

$$
\varepsilon=\left(\frac{\lambda}{D \operatorname{Cos} \theta}-\beta\right) \frac{1}{\tan \theta}
$$


The lattice distortion (LD) developed in thin films can be evaluated from the relation [26]

$$
\mathrm{LD}=\frac{\beta}{4 \tan \theta}
$$

The stacking fault probability $(\alpha)$ with peak shift $\Delta(2 \theta)$ is given by warren Warehouse developed in thin films can be evaluated from the relation

$$
\alpha=\frac{2 \pi^{2}}{45 \sqrt{3}} \frac{\Delta(2 \theta)}{\tan \theta}
$$

The calculated lattice constant, crystallite size, dislocation density, strain, stacking fault probability and micro structures are presented in Table - 1 .

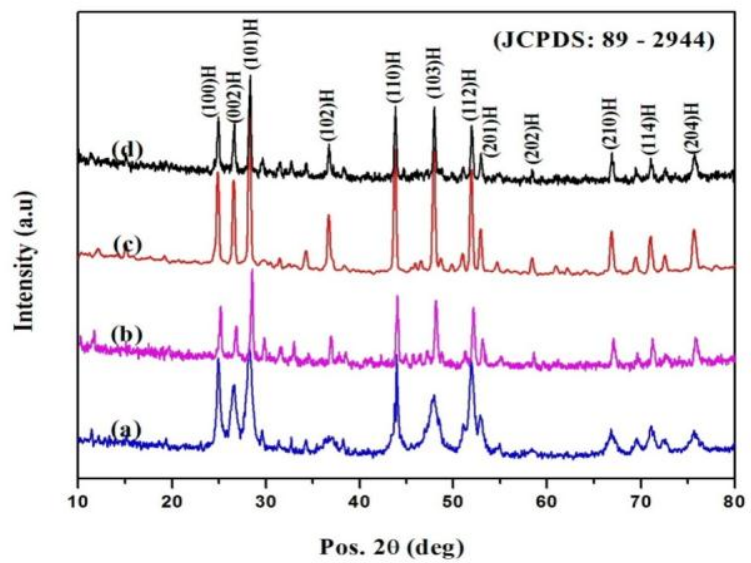

Fig. 1 (a-d). The X-ray diffraction patterns for CdS Nanoparticles

Table - 1: Micro Structural Properties of CdS nanoparticles

\begin{tabular}{|c|c|c|c|c|}
\hline Material & CdS & $\begin{array}{c}\text { Ni - } \\
\text { Doped } \\
\text { CdS }\end{array}$ & $\begin{array}{c}\text { Ba - } \\
\text { Doped } \\
\text { CdS }\end{array}$ & $\begin{array}{c}\text { (Ni \& Ba) } \\
\text { co - Doped } \\
\text { CdS }\end{array}$ \\
\hline c/a & 1.62 & 1.62 & 1.63 & 1.62 \\
\hline $\begin{array}{c}\text { Crystallite } \\
\text { Size, D }\left(10^{-}\right. \\
\text {m })\end{array}$ & 32.45 & 49.37 & 77.03 & 59.61 \\
\hline $\begin{array}{c}\text { Dislocation } \\
\text { density, } \delta \times \\
\left(10^{16} \text { lines/m) }\right.\end{array}$ & 9.4967 & 4.1027 & 1.6853 & 2.8143 \\
\hline $\begin{array}{c}\text { Micro Strain, } \\
\varepsilon^{\times} \\
\left(10^{-3} \text { Lines }^{-2}\right. \\
\left.\mathrm{m}^{-4}\right)\end{array}$ & 0.1054 & 0.0452 & 0.07411 & 0.0597 \\
\hline $\begin{array}{c}\text { Lattice } \\
\text { Distortion } \\
(\mathrm{LD}) \times\left(10^{-3}\right)\end{array}$ & 8.162 & 2.881 & 1.794 & 2.388 \\
\hline \multicolumn{2}{|c|}{$\times$} & & \\
\hline
\end{tabular}

\section{Surface Morphological Studies}

Fig. 2. Shows the morphology of undoped, $\mathrm{Ni}, \mathrm{Ba}$ and $\mathrm{Ni} \&$ $\mathrm{Ba}$ co-doped $\mathrm{CdS}$ nanoparticles at $500 \mathrm{~nm}$ magnifications. Figures 2(a), (b), (c), and (d) show the SEM images of pure CdS, CdS: $\mathrm{Ni}_{\mathrm{x}}, \mathrm{Ba}_{\mathrm{x}}$ and $\mathrm{Ni}_{\mathrm{y}}$ co-doped $\mathrm{Ba}_{\mathrm{y}}(\mathrm{x}=10 \%$ and $\mathrm{y}=5 \%)$ respectively. SEM images showed the agglomerated nanoparticles of the prepared samples. From Fig. 2(a) the SEM result revealed that the grains are uneven and different in sizes with some void and cracks are found which indicate that the agglomeration process is highly occurred for undoped CdS samples. But in the Fig 2(b, c and d) the grains are in more or less in spherical shape which indicates that the doping content that is slow down the agglomeration of $\mathrm{CdS}$ Nps. The SEM image showed that the agglomeration process is occurred slowly down with the Ba content doped $\mathrm{CdS}$ NPs.

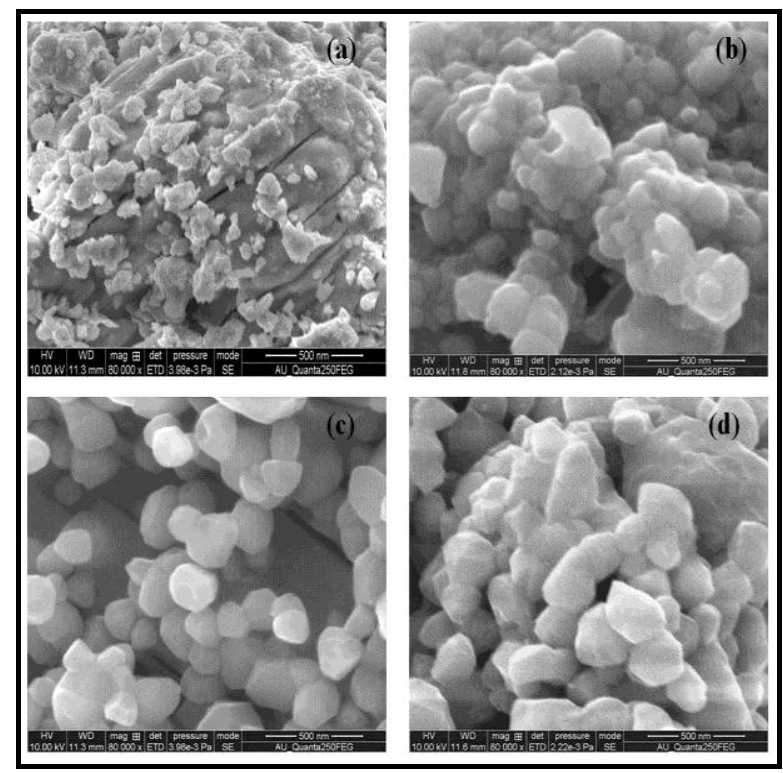

Fig. 2. SEM images of (a) Undoped CdS (b) Ni doped CdS (c) Ba doped CdS (d) Ni \& Ba co-doped CdS Nano particles

\section{Optical studies:}

The optical absorption spectra of undoped and $\mathrm{Ni}, \mathrm{Ba}$ and codoped CdS nanoparticles are recorded by UV - Vis. NIR spectrometer. The absorbance as a function of wavelength is given in fig. 4. The absorbances depict a sharp fall at the band edge implying the good crystal quality of the CdS nanostructure. the absorbance values is around $483 \mathrm{~nm}$ for all the CdS nano powders.

The wavelength dependence of the optical transmittance spectra for the pure, $\mathrm{Ni}, \mathrm{Ba}$ and $\mathrm{Ni}-\mathrm{Ba}$ co-doped $\mathrm{CdS}$ are shown in figure - 3 measured at the room temperature. From the transmittance spectra, the average optical transmissions are achieved at the visible region. The values of $m$ depends upon the type of the transition; which may have values $1 / 2$, 2 , and $3 / 2$ corresponding to the allowed direct, allowed indirect, and forbidden direct transitions respectively [29]. It is due to the direct band-to-band transition. The band gaps are found to be $2.56 \mathrm{eV}, 2.54 \mathrm{eV}, 2.35 \mathrm{eV}$ and $2.48 \mathrm{eV}$ for undoped, Ni doped, Ba doped and $\mathrm{Ni} \& \mathrm{Ba}$ co-doped $\mathrm{CdS}$ nanostructure. Development of semiconductor film with controllable energy gap is necessary due to the increased application in solar cell fabrication and opto-electronic devices. 


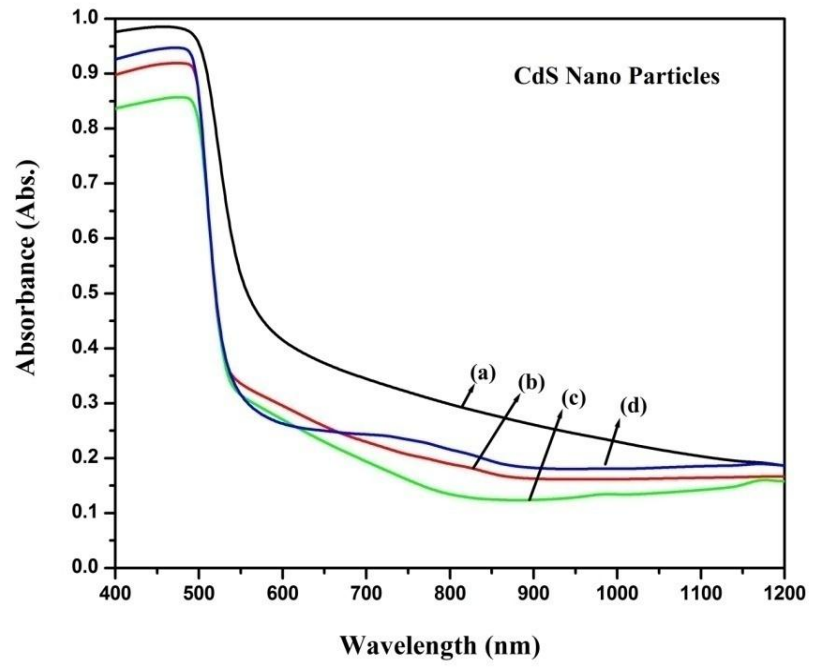

Fig. 4. (i). Absorbance spectra of (a) Undoped, (b) Ni, (c) Ba and (d) Ni \& Ba co-doped CdS Nano particles

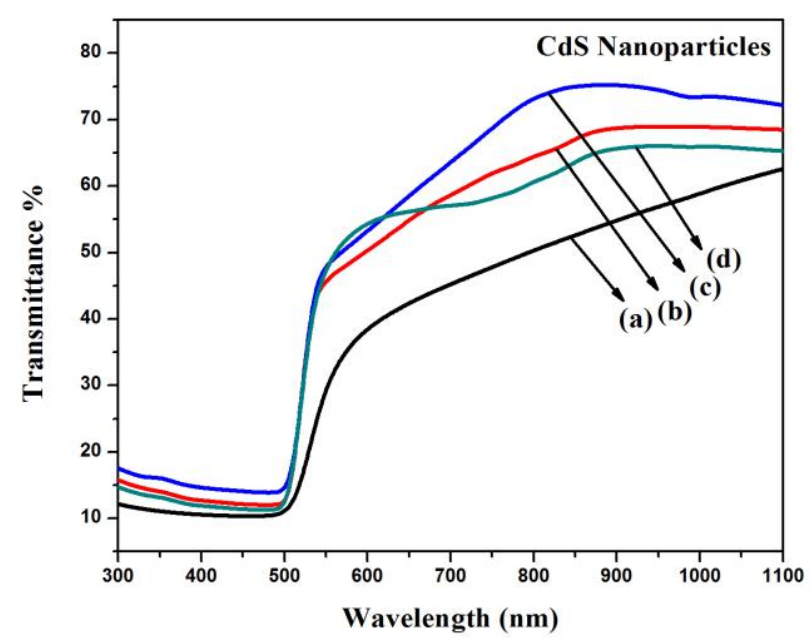

Fig. 4. (ii). Transmission spectra of (a) Undoped, (b) Ni, (c) Ba and (d) $\mathrm{Ni}$ $\&$ Ba co-doped CdS Nano particles

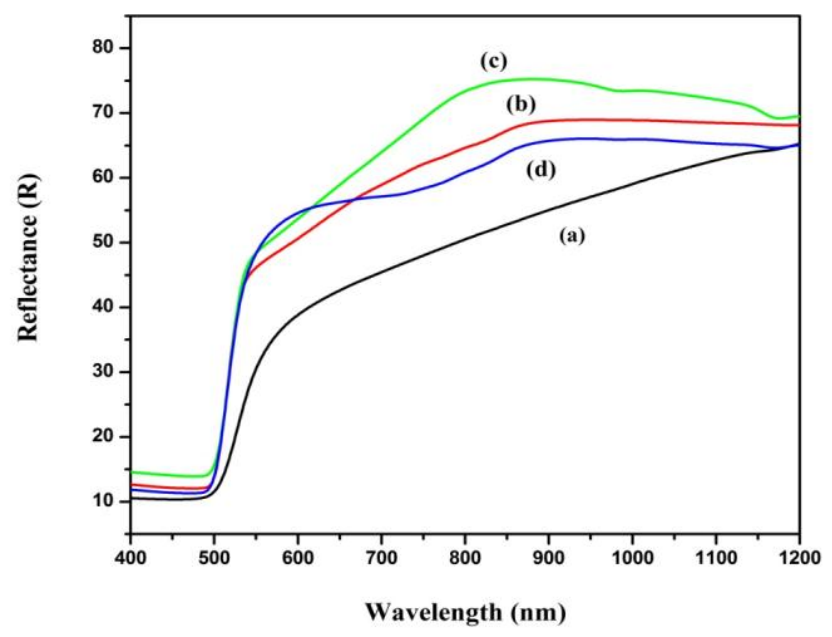

Fig. 4. (iii). Reflectance spectra of (a) Undoped,

(b) Ni, (c) Ba and (d) Ni \& Ba co-doped CdS Nano particles

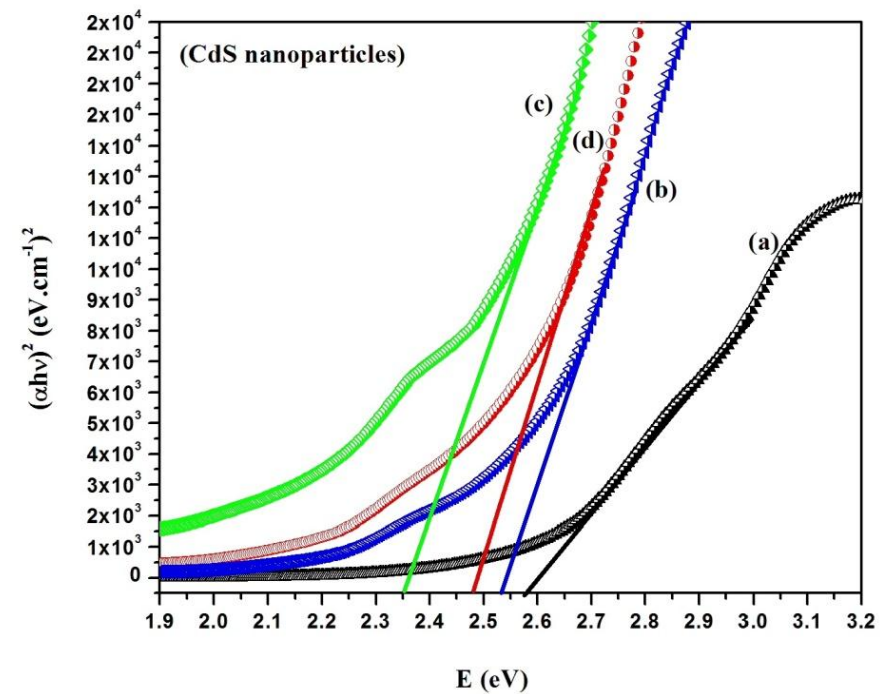

Fig. 4.4 (iv). Tauc's plot of of (a) Undoped, (b) Ni, (c) Ba and (d) $\mathrm{Ni} \& \mathrm{Ba}$ co-doped CdS Nano particles

\section{CONCLUSION}

In summary, $\mathrm{Ni}$ and $\mathrm{Ba}$ co-doped $\mathrm{CdS}$ nano particles have been successfully synthesized by chemical co-precipitation method using analytical grade Cadmium Chloride and Sodium Sulphide chemicals. The X-ray diffraction pattern confirms the formation of hexagonal structure (fcc) of $\mathrm{CdS}$ and the peaks are identified with the JCPDS (89-2944). The corresponding intensity of peak is increased with increased dopant materials. The peak shift is obtained for both $\mathrm{Ni}$ and Ba doped CdS NPs and the crystallite size increased for the sample (c) because the ionic radii is high for Ba to the host CdS. The micro structural parameters were calculated.

The absorbance and transmittance values are high in the visible region and their spectra for all samples have sharp fall edge near to the band edge which indicates the formation of nano size CdS particles. The band gap is small to the $\mathrm{Ba}$ doped $\mathrm{CdS}$ which exhibit the quantum confinement effect.

The SEM image indicates that the particles are more or less in spherical shape for doped CdS samples. The SEM image showed that the agglomeration process is occurred slowly down with the addition of doping content.

\section{REFERENCES}

[1]. Zhao, Jialong, et al. "Efficient CdSe/CdS quantum dot lightemitting diodes using a thermally polymerized hole transport layer." Nano letters, Vol. 6, Issue. 3, pp 463-467, 2006.

[2]. Li L, Wang W, Liu H, Liu X, Song Q, Ren S. "First principles calculations of electronic band structure and optical properties of Cr-doped ZnO”. The Journal of Physical Chemistry C, Vol. 113, Issue. 19, pp 8460-8464, 2009. 
[3]. Y.J. Chan, S. Steckel, P.T. Snee, J.M. Caruge, J.M. Hodgkiss, D.G. Nocera, M.G. Bawendi. Appl. Phys. Lett. Vol. 86, pp $073102,2005$.

[4]. P. Gupta, A. Ulman, S. Fan, A. Korniakov, K. Loos, J. Am. Chem. Soc. Vol. 127, Issue. 1, pp 4, 2005.

[5]. Jian D, Gao Q. "Synthesis of $C d S$ nanocrystals and $A u / C d S$ nanocomposites through ultrasound activation liquid-liquid twophase approach at room temperature". Chemical Engineering Journal. Vol. 121, Issue. 1, pp 9-16, 2006.

[6]. Favier, V., J. Y. Cavaille, G. R. Canova, and S. C. Shrivastava. "Mechanical percolation in cellulose whisker nanocomposites." Polymer Engineering \& Science, Vol. 37, Issue. 10, pp 1732-1739, 1997.

[7]. Alivisatos, A. Paul. "Perspectives on the physical chemistry of semiconductor nanocrystals." The Journal of Physical Chemistry, Vol. 100, Issue. 31, pp 13226-13239, 1996.

[8]. Henglein, Arnim. "Small-particle research: physicochemical properties of extremely small colloidal metal and semiconductor particles." Chemical reviews, Vol. 89, Issue. 8, pp 1861-1873, 1989.

[9]. Ch. Tao, S. Zheng, H. Möhwald, J. Li.. Langmuir Vol. 19, Issue. 21, pp 9039, 2003.

[10]. Barglik-Chory, Ch, et al. "Adjustment of the band gap energies of biostabilized CdS nanoparticles by application of statistical design of experiments." The Journal of Physical Chemistry B, Vol. 108, Issue. 23, pp 7637-7640, 2004.

[11]. Wankhede, Manoj E., and Santosh K. Haram. "Synthesis and Characterization of $\mathrm{Cd}-\mathrm{DMSO}$ Complex Capped CdS Nanoparticles." Chemistry of materials, Vol. 15, Issue. 6, pp 12961301, 2003.

[12]. Simmons, Blake A., et al. "Morphology of CdS nanocrystals synthesized in a mixed surfactant system." Nano Letters, Vol. 2, Issue. 4, pp 263-268, 2002.

[13]. Curri, Maria Lucia, et al. "Synthesis and characterization of $C d S$ nanoclusters in a quaternary microemulsion: the role of the cosurfactant." The Journal of Physical Chemistry B, Vol. 104, Issue. 35, pp 8391-8397, 2000.

[14]. DE LA CRUZ TERRAZAS, E. C., RC Ambrosio Lázaro, ML Mota González, P. A. Luque, S. J. Castillo, and A. CarrilloCastillo. " A Simple method for the synthesis of CdS nanoparticles using a novel surfactant", Chalcogenide Letters, Vol. 2, Issue. 4, 2015.

[15]. Dumbrava, A., et al. "Synthesis and characterization of cadmium sulfide obtained at room temperature." Chalcogenide Lett, Vol. 7, Issue. 2, pp 111-118, 2010.

[16]. M. Maleki, M.S. Ghamsari, Sh. Mirdamadi and R. Ghasemzadeh,. Quantum Electron \& Optoelectron., Vol. 10, pp 30-32, 2007.

[17]. Pattabi, M. and Uchil, J., Synthesis of cadmium sulphide nanoparticles. Solar energy materials and solar cells, Vol. 63, Issue. 4, pp 309-314, 2000.

[18]. Elilarassi, R., S. Maheshwari, and G. Chandrasekaran. "Structural and optical characterization of CdS nanoparticles synthesized using a simple chemical reaction route." Optoelectron. Adv. Mater, Vol. 4, pp 309-312, 2010.

[19]. Fu, Tiexiang. "Sensing behavior of CdS nanoparticles to SO2, H2S and NH3 at room temperature." Materials Research Bulletin, Vol. 84, Issue. 5, pp 1784-1790, 2013.

[20]. Phuruangrat, Anukorn, Titipun Thongtem, and Somchai Thongtem. "Characterisation of one-dimensional CdS nanorods synthesised by solvothermal method." Journal of Experimental Nanoscience, Vol. 4, Issue. 1, pp 47-54, 2009.

[21]. Murali, G., et al. "Structural and optical response of mixed phase $\mathrm{CdS}$ nanocrystals to $\mathrm{Ni}^{2+}$ ions." IOP Conference Series: Materials Science and Engineering. Vol. 73. No. 1. IOP Publishing, 2015.
[22]. Marandi, M., N. Taghavinia, and S. M. Mahdavi. "A photochemical method for controlling the size of CdS nanoparticles." Nanotechnology, Vol. 16, Issue. 2, pp 334, 2005.

[23]. Tong, Hua, and Ying-Jie Zhu. "Synthesis of CdS nanocrystals based on low-temperature thermolysis of one single-source organometallic precursor." Nanotechnology, Vol. 17 Issue. 3, pp $885,2006$.

[24]. Singh, Vineet, and Pratima Chauhan. "Structural and optical characterization of CdS nanoparticles prepared by chemical precipitation method." Journal of Physics and Chemistry of Solids, Vol. 70, Issue. 7, pp 1074-1079, 2009.

[25]. Chandramohan, S., A. Kanjilal, S. N. Sarangi, S. Majumder, R. Sathyamoorthy, and T. Som. "Implantation-assisted Co-doped CdS thin films: Structural, optical, and vibrational properties." Journal of Applied Physics, Vol. 106, Issue. 6, pp $063506,2009$.

[26]. Jia, Xiaohua, Huiqing Fan, Mohammad Afzaal, Xiangyang Wu, and Paul O'Brien. "Solid state synthesis of tin-doped $\mathrm{ZnO}$ at room temperature: characterization and its enhanced gas sensing and photocatalytic properties." Journal of hazardous materials, Vol. 193, pp 194-199, 2011.

[27]. Chandrasekar, L. Bruno, R. Chandramohan, R. Vijayalakshmi, and S. Chandrasekaran. "Preparation and characterization of Mndoped ZnS nanoparticles." International Nano Letters, Vol. 5, Issue. 2, pp 71-75, 2010.

[28]. Dawar, A. L., P. K. Shishodia, G. Chauhan, A. Kumar, and P. C. Mathur. "Growth of high-mobility $C d S$ thin films." Journal of Materials Science Letters, Vol. 9, Issue. 5, pp 547-548, 1990.

[29]. Sharma, P., V. Sharma, and S. C. Katyal. "Variation of optical constants in Ge10Se60Te30 thin film." Chalcogenide letters, Vol. 3, Issue. 10, pp 73-79, 2006.

\section{AUTHORS PROFILE}

Dr. M.Karunakaran is currently working as an Assistant Professor in Department of Physics, Alagappa Government Arts College, Karaikudi. He has published more than 50 research papers in reputed international journals and it's also available online. His main research work focuses on

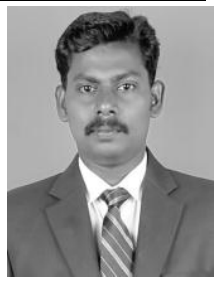
Materials Science (Thin films and Nano materials synthesis) He has 13 years of teaching experience and 10 years of research experience.

Mr. K.Kasirajan perused M. Phil., (Physics) in 2015 from Alagappa Government Arts College, Karaikudi, (TN), India. Currently, he is doing Ph.D. from Alagappa University, Karaikudi, (TN), India. His area of research is Synthesis and Characterization of Dilute magnetic

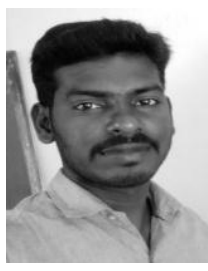
Semiconducting thin films, Nanoparticles and Green Synthesis etc. He has published more than 20 papers in International Journals. 